\title{
A Research on The Formability of PVC Sheet in Single Point Incremental Forming (SPIF) Technology
}

\author{
Nguyen Thanh Nam ${ }^{1,}{ }^{*}$, Nguyen Hoang Hiep ${ }^{2}$, Nguyen Tan Hung ${ }^{3}$, Tran Trong Hy ${ }^{4}$, Ho Huu \\ $\mathrm{Han}^{5}$ \\ ${ }^{1}$ Faculty of Mechanical Engineering, Industrial University of Ho Chi Minh City, Vietnam \\ ${ }^{2}$ Faculty of Mechanical Engineering, Vinh Long University of Technology Education \\ ${ }^{3}$ Cao Thang Technical College \\ ${ }^{4}$ Faculty of Mechanical Engineering, Ho Chi Minh City University of Technology, Vietnam \\ ${ }^{5}$ Saigon Technology University (STU), Faculty of Mechanical Engineering, Vietnam
}

\begin{abstract}
Nowadays Single Point Incremental Forming (SPIF) is really a new technology of forming metal sheet after its formation and long development in about five decades. Although it was invented in, 1967 by Leszak, an American inventor, but the applications of the innovative technology have just been popular from 1990 because of the advance of controlling technology. This technology is especially adapted to small batch, unique or single productions. In almost all cases, the workpiece material sheets are metal such as aluminum alloys, bronze, mild steel, stainless steel and even Titanium with lot of researches, papers and thesis... Nonmetal sheets are rarely applied in this technology because of rare application. Nowadays, on the rise of the development of composite materials such as, PVC, thermoplastic resins... that have been a lot of applications on living life and technology. In this paper, we dedicate all of our work in the examination some parameters of forming that influence on the deformable ability of PVC plastic by empirical method under the support of DOE and Minitab software. This paper also provides our own experiences in forming PVC sheet that we had performed in the recent decade.
\end{abstract}

\section{INTRODUCTION}

In Single Point Incremental Forming (SPIF) technology, the non-cutter tool applies the forming forces on only one side of the sheet workpiece to form concave shapes on workpiece sheet. Beside SPIF there is Two Point Incremental Forming (TPIF) wherein the tools apply forces on both sides of the workpiece that could be formed complex convex and concave surfaces on model as shown in Figure 1. They are 2 branches of a state-of-the-art sheet forming without die technology invented by Leszak in 1967 [1] under the terminology of Incremental Forming Sheet (ISF). This forming sheet technology is suitable only for single

\footnotetext{
${ }^{*}$ Corresponding author: nguyenthanhnam@iuh.edu.vn
} 
or small batch production. Two branches of ISF: Single point Incremental Forming (SPIF) and Two Point Incremental Forming (TPIF) are illustrated in Figure 1.

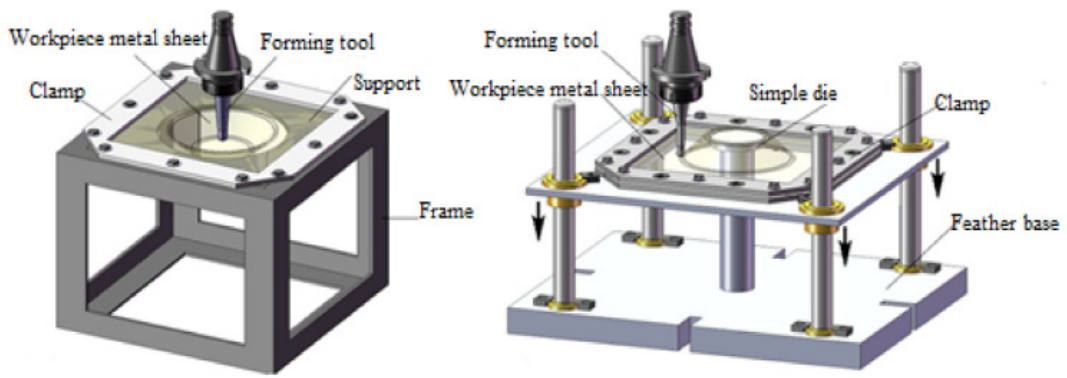

Fig. 1 a. Single Point Incremental Forming (SPIF) b. Two Point Incremental Forming (TPIF) [2]

At the beginning, this method is applied for forming metal sheets, but with the bloom of plastic or PVC based materials there are also researches of ISF for PVC material. In paper [3], the authors research the post-forming properties of thermoplastic polymer. Their results show that the post-ISF-process tensile properties is decreased, and the strain is increased in their experiment ranges. In research [4], the authors present the new methodology to find plastic flow and failure in the PVC sheets forming by the ISF process. These research helps us to clarify how plastic deform under ISF process, also help us know the modification of mechanical properties. But these studies only deal with basic parameters and do not study the effect of temperature, an important technological parameter, on the ISF processes. Therefore, we need to understand the influence of temperature parameter on this process, which is also the main goal of this study.

\subsection{Mechanical properties of PVC}

The mechanical properties of PVC sheet are given in Table 1 [5].

Table 1. Typical Properties of PVC [5]

\begin{tabular}{|c|c|c|c|}
\hline \multicolumn{4}{|c|}{ TYPICAL PROPERTIES of PVC and CPVC } \\
\hline ASTM or UL test & Property & PVC & CPVC \\
\hline \multicolumn{4}{|c|}{ PHYSICAL } \\
\hline D792 & $\begin{array}{l}\text { Density }\left(\mathrm{lb} / \mathrm{in}^{3}\right) \\
\left(\mathrm{g} / \mathrm{cm}^{3}\right)\end{array}$ & $\begin{array}{l}0.051 \\
1.41\end{array}$ & $\begin{array}{c}0.055 \\
1.52\end{array}$ \\
\hline D570 & Water Absorption, 24 hrs (\%) & 0 & 0.04 \\
\hline \multicolumn{4}{|c|}{ MECHANICAL } \\
\hline D638 & Tensile Strength (psi) & 7,500 & 8,200 \\
\hline D638 & Tensile Modulus (psi) & 411,000 & 430,000 \\
\hline D638 & Tensile Elongation at Break (\%) & - & 27 \\
\hline D790 & Flexural Strength (psi) & 12,800 & 15,000 \\
\hline D790 & Flexural Modulus (psi) & 481,000 & 410,000 \\
\hline D785 & Hardness & 115 (Rockwell R) & 121 (Rockwell R) \\
\hline D256 & IZOD Notched Impact (ft-lb/in) & 1.0 & 1.6 \\
\hline
\end{tabular}

\subsection{Selection of model of experiment}

The deformability of a material stands for by the angle $\alpha$ that is made by the tangent at the forming point on the workpiece sheet and the horizontal line at this point. The deeper the position of formed point the bigger of the forming angle. According to a lot of researches, 
this deformable angle depends on each sheet material and ways of forming and it cannot pass it limitation value of about $80^{\circ}$ [6]. In order to examine exactly the angle by experimental process, almost all researches on SPIF technology also select the model on figure 2 because at any random torn point $\mathrm{M}$, we could measure the depth $\mathrm{z}$ and deduce the deformable angle by this formula: $\boldsymbol{\alpha}=\arccos \left(\frac{R-z}{R}\right)$. In the current time, standard market plates of PVC sheet are provided by dimension of $1000 \times 2000$, so in saving material we selected a square workpiece of $250 \times 250$ with no remain stub. After subtraction of the meadow the remained working circle is $\varnothing 200$.

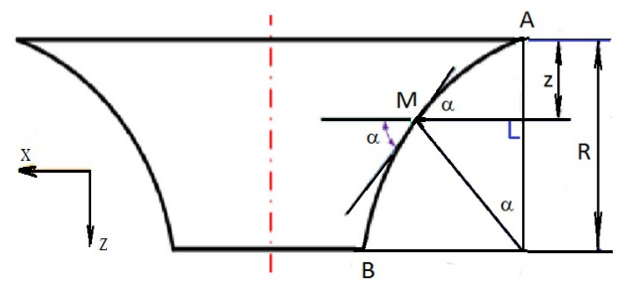

Fig. 2: SPIF model used in experiment

\section{Design of Experiment on The Formability of PVC Sheet in SPIF}

\subsection{Selection of investigated forming parameters and method of design of experiment (DOE}

In our work, there are many forming parameters that influence to the formability of the metal sheet workpiece such as diameter of tool $\mathrm{d}$, the vertical feed rate $\Delta \mathrm{z}$, the velocity of tool in horizontal plane $\mathrm{V}$ and the temperature $\mathrm{T}$ of $\mathrm{PVC}$ sheet when forming. By our own experiment, properties and ability of specialist SPIF machine (figure 2) and based on DOE we selected of 2 limited values of 4 variable input parameters that are suitable to the properties of machine, tool and PVC sheet:

- The vertical feed rate after each orbit $\Delta \mathrm{z}=0,4-1,2 \mathrm{~mm}$,

- The diameter of tool $\mathrm{d}=6-12 \mathrm{~mm}$

- The velocity of tool in horizontal plane $\mathrm{v}=1000-2500 \mathrm{~mm} / \mathrm{min}$

- The temperature $\mathrm{T}$ of PVC sheet when forming $\mathrm{T}=30^{\circ}-60^{\circ}$ (according to [5] the maximum working temperature of PVC is only $140^{\circ} \mathrm{F}$ or $60^{\circ} \mathrm{C}$ )

Beside 4 above parameters we selected 3 constant values:

-The thickness of workpiece sheet is $2 \mathrm{~mm}$ the popular thickness of almost all PVC sheet in market.

-The number of revolutions per minute $\mathrm{n}=900 \mathrm{rpm}$.

- SAE 40 oil is selected as lubricant at ambient temperature in South of Vietnam $\left(30^{\circ} \mathrm{C}\right)$ as lowest and $60^{\circ} \mathrm{C}$ as selected high temperature.

In the purpose of saving effort in experiment according to [6] there are many experiments involve the study of the effects of 4 factors we could apply the factorial designs that is most efficient for this type of experiment. By a factorial DOE with 4 factors, each factor has 2 levels the number of experiments in forming model is $\mathrm{N}=2^{\mathrm{k}-\mathrm{p}}=2^{4-1}=8$,

Wherein:

- $\quad \mathrm{N}$ : the number of forming model,

- $\mathrm{k}=4$ is number of factors,

- $\mathrm{p}=1$, number of replaced factor, 
The number of iteration [7]: $\mathrm{m}=\mathrm{t}^{2} \cdot \mathrm{s}^{2} / \Delta^{2}=2,145$, selected value is 3 . Finally, the total number of experiments is N.m=8.3=24. Table 2 illustrates all limited value and coded of 4 influential parameters.

Table 2. Table of natural and coded influential parameters

\begin{tabular}{|c|c|c|c|c|c|c|}
\hline \multicolumn{2}{|c|}{ Parameters } & \multicolumn{2}{c|}{ Limited value } & \multicolumn{2}{c}{} \\
\cline { 1 - 5 } Nominal name & \multicolumn{2}{|c|}{ Symbol } & \multicolumn{2}{c}{} \\
\cline { 2 - 6 } & Natural & Coded & Lowest & Highest & $\begin{array}{c}\text { Mean } \\
\text { value }\end{array}$ & $\begin{array}{c}\text { Variable range } \\
\text { to mean value }\end{array}$ \\
\hline $\begin{array}{c}\text { Vertical feed rate } \\
\text { (mm) }\end{array}$ & $\Delta \mathrm{z}$ & $\mathrm{x} 1$ & 0.4 & 1.2 & 0.8 & 0.4 \\
\hline $\begin{array}{c}\text { Diameter of tool } \\
\text { (mm) }\end{array}$ & $\mathrm{D}$ & $\mathrm{x} 2$ & 6 & 12 & 9 & 3 \\
\hline $\begin{array}{c}\text { Velocity of tool } \\
\text { in horizontal } \\
\text { plane (mm/min) }\end{array}$ & $\mathrm{F}$ & $\mathrm{x} 3$ & 1000 & 2500 & 1750 & 750 \\
\hline $\begin{array}{c}\text { Forming } \\
\text { temperature, }{ }^{0} \mathrm{C}\end{array}$ & $\mathrm{T}$ & $\mathrm{x} 4$ & 30 & 60 & 45 & 15 \\
\hline
\end{tabular}

The temperature $\mathrm{T}(\mathrm{x} 4)$ was selected as the replaced parameter so we could perform the matrix of partial factors as in the following table.

Table 3: Table of coding parameters in Partial factor DOE

\begin{tabular}{|c|c|c|c|c|}
\hline$N_{0}$ & $\mathrm{x} 1$ & $\mathrm{x} 2$ & $\mathrm{x} 3$ & $\mathrm{x} 4=\mathrm{x} 1 \mathrm{x} 2 \mathrm{x} 3$ \\
\hline 1 & -1 & -1 & -1 & -1 \\
2 & +1 & -1 & -1 & +1 \\
3 & -1 & +1 & -1 & +1 \\
4 & +1 & +1 & -1 & -1 \\
5 & -1 & -1 & +1 & +1 \\
6 & +1 & -1 & +1 & -1 \\
7 & -1 & +1 & +1 & -1 \\
8 & +1 & +1 & +1 & +1 \\
\hline
\end{tabular}

\subsection{Simulation of the SPIF process by ProEngineer to guess the experimental} result

The simulation of SPIF process has to perform with the same value of experimental process but have no iteration because there are no influential random parameters such as in experiment. All the properties of PVC are adapted from table 1 to ProEngineer when simulating. One of the results is displayed in figure 4 that confirms the application of SPIF for PVC sheet. 


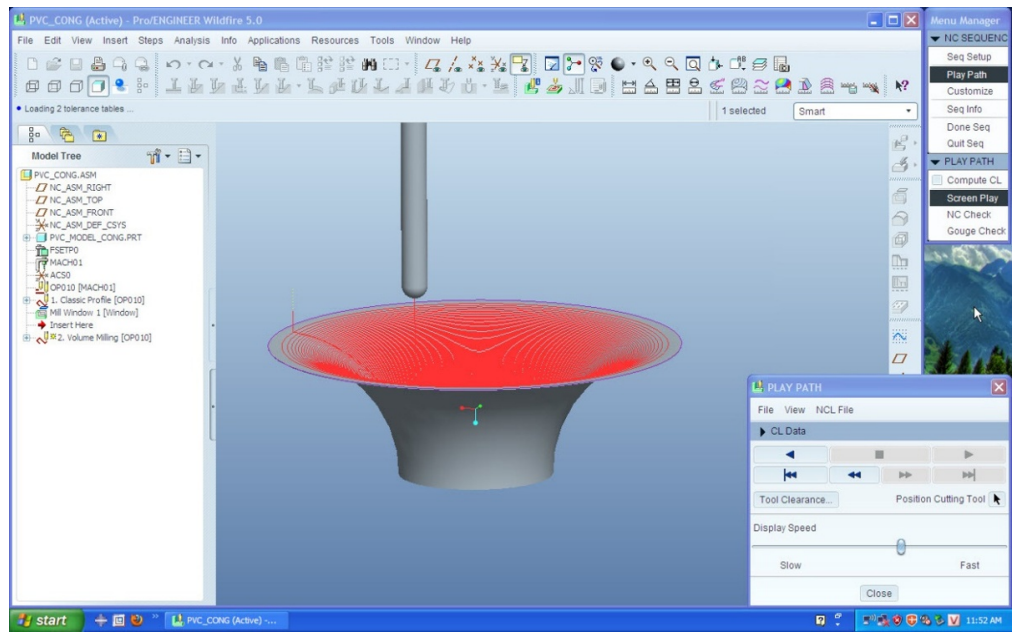

Fig. 3: A result of SPIF PVC model by Pro/E with $h=60 \mathrm{~mm}, \varnothing=200 \mathrm{~mm}$

\subsection{Specialized SPIF machine, Clamping \& heating feature, and tool to perform PVC models}

All traditional CNC milling machine could be used to perform all the experimental PVC models. Fortunately, by the previous projects we already manufactured a specialized SPIF machine so all of our experiments of forming on PVC model were perform in achieved in Specialized SPIF machine in CAD-CAM workshop of DCSELAB. Material of tool (pestle) is high speed steel (HSS) with cylindrical shank and no-cutting edges spherical end tip as in figure 4. In order to control the temperature of PVC sheet when forming 24 models we designed and manufactured a typical feature that has 2 functions: Clamping and controlling the limited temperature for PVC sheet. All the structure of clamping and controlling heat are displayed in figure 5 .
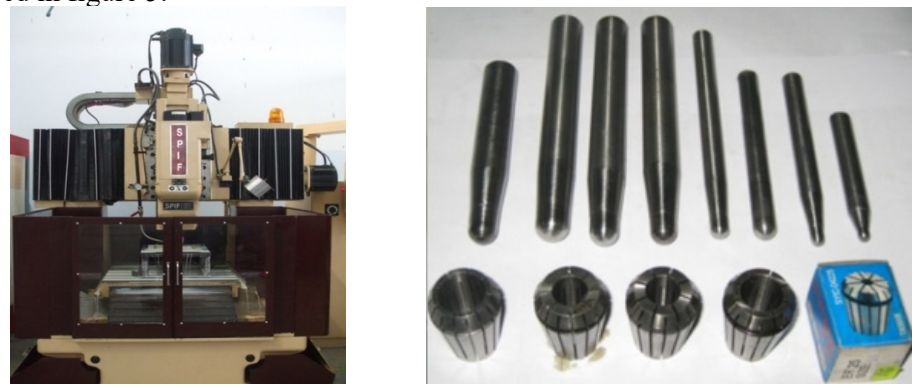

Fig. 4: a. Specialized SPIF machine of DCSELAB; b. Self-manufactured tools and Standard bores collets 


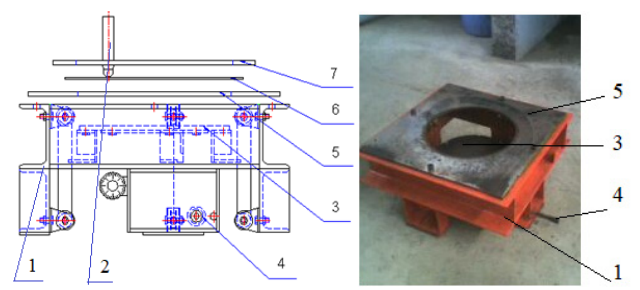

Fig. 5: a. Drawing of clamping and controlling heat feature b. Manufactured feature

1. Frame of feature, 2. Tool, 3. Flexible thermostat, 4 adjustable control knob 5. Model support

6. PVC workpiece sheet, 7. Clamp plate

There are 2 regimes of heating: $30^{\circ} \mathrm{C}$ thermostat is off, $60^{\circ} \mathrm{C}$ thermostat is on.

\section{PERFORMING, MEASURING AND treatment the results OF PVC MODELS}

\subsection{Performing and measuring PVC models for the deformability}

PVC sheet with thickness of $2 \mathrm{~mm}$ are cut and bend into workpiece of 250x250 (mm) and clamped in feature to be formed as in figure 6.

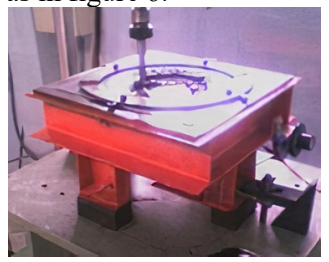

Fig. 6: Forming PVC model on integrated future at DCSELAB workshop [6]

The formed PVC models that are formed to reach torn point are measured and statistical are illustrated in figure 7.
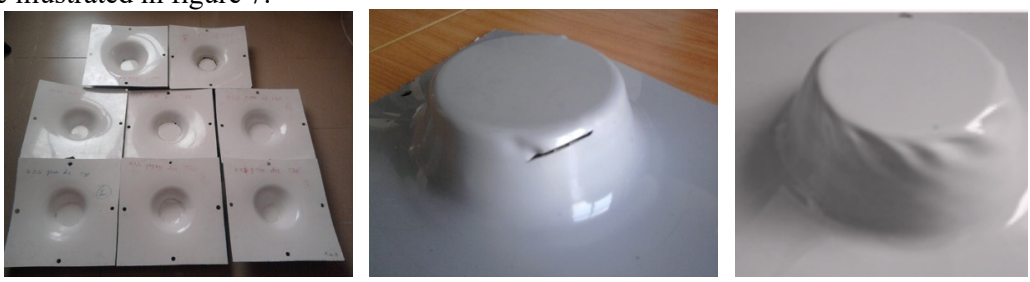

Fig. 7: PVC model are formed to get torn lines or failures to reach a biggest angle of deformation [6]

\subsection{Treatment the result}

The values of deformable angle are displayed in table 4 and calculated the mean value in table 5 . 
Table 4: Coarse result of deformable angle of forming of 24 models in 3 times of iteration

\begin{tabular}{|c|c|c|c|c|c|c|c|}
\hline \multirow{2}{*}{$\mathrm{N}^{0}$} & \multicolumn{3}{|c|}{ Influential parameters } & \multicolumn{3}{|c|}{$\begin{array}{c}\text { Results } \\
\text { of } \alpha_{\max }\end{array}$} \\
\cline { 2 - 8 } & $\begin{array}{c}\Delta \mathrm{z} \\
(\mathrm{mm}) \\
\mathrm{x} 1\end{array}$ & $\begin{array}{c}\mathrm{d} \\
(\mathrm{mm}) \\
\mathrm{x} 2\end{array}$ & $\begin{array}{c}\mathrm{v} \\
(\mathrm{mm} / \mathrm{min}) \\
\mathrm{x} 4\end{array}$ & $\begin{array}{c}\mathrm{T} \\
\left({ }^{0} \mathrm{C}\right) \\
\mathrm{x} 4\end{array}$ & $\mathrm{y} 1$ & $\mathrm{y} 2$ & $\mathrm{y} 3$ \\
\hline 1 & 0,4 & 6 & 1000 & 30 & 50 & & \\
\hline 2 & 0,4 & 6 & 1000 & 30 & & 53 & \\
\hline 3 & 0,4 & 6 & 1000 & 30 & & & 53 \\
\hline 4 & 1,2 & 6 & 1000 & 60 & 65 & & \\
\hline 5 & 1,2 & 6 & 1000 & 60 & & 63 & \\
\hline 6 & 1,2 & 6 & 1000 & 60 & & & 63 \\
\hline 7 & 0,4 & 12 & 1000 & 60 & 65 & & \\
\hline 8 & 0,4 & 12 & 1000 & 60 & & 65 & \\
\hline 9 & 0,4 & 12 & 1000 & 60 & & & 66 \\
\hline 10 & 1,2 & 12 & 1000 & 30 & 60 & & \\
\hline 11 & 1,2 & 12 & 1000 & 30 & & 63 & \\
\hline 12 & 1,2 & 12 & 1000 & 30 & & & 60 \\
\hline 13 & 0,4 & 6 & 2500 & 60 & 65 & $\ldots$ & $\ldots$ \\
\hline 14 & 0,4 & 6 & 2500 & 60 & & 65 & \\
\hline 15 & 0,4 & 6 & 2500 & 60 & & & 65 \\
\hline 16 & 1,2 & 6 & 2500 & 30 & 65 & & \\
\hline 17 & 1,2 & 6 & 2500 & 30 & & 62 & \\
\hline 18 & 1,2 & 6 & 2500 & 30 & & & 62 \\
\hline 19 & 0,4 & 12 & 2500 & 30 & 55 & & \\
\hline 20 & 0,4 & 12 & 2500 & 30 & & 57 & \\
\hline 21 & 0,4 & 12 & 2500 & 30 & & & 57 \\
\hline 22 & 1,2 & 12 & 2500 & 60 & 65 & & \\
\hline 23 & 1,2 & 12 & 2500 & 60 & & 68 & \\
\hline 24 & 1,2 & 12 & 2500 & 60 & & & 66 \\
\hline 3
\end{tabular}

Table 5: Mean deformable angle ready for statistics

\begin{tabular}{|c|c|c|c|c|c|}
\hline $\mathrm{N}_{0}$ & $\mathrm{x} 1$ & $\mathrm{x} 2$ & $\mathrm{x} 3$ & $\mathrm{x} 4=\mathrm{x} 1 \mathrm{x} 2 \mathrm{x} 3$ & $\bar{y}=\alpha \max$ \\
\hline 1 & -1 & -1 & -1 & -1 & 52,00 \\
2 & +1 & -1 & -1 & +1 & 63,67 \\
3 & -1 & +1 & -1 & +1 & 65,33 \\
4 & +1 & +1 & -1 & -1 & 61,00 \\
5 & -1 & -1 & +1 & +1 & 65,00 \\
6 & +1 & -1 & +1 & -1 & 63,00 \\
7 & -1 & +1 & +1 & -1 & 56,33 \\
8 & +1 & +1 & +1 & +1 & 66,33 \\
\hline
\end{tabular}

From the result in table 5, we could deduce the following regression equation of the deformability of the PVC sheets:

The regression equation of deformable angle in encoding shape:

$y=61,5833+1,9167 x 1+0,6667 . x 2+1,0833 x 3-2 . x 2 \times 3+3,5 . x 4$

After decoding, we get the regression equation of deformable angle:

$\alpha=20,6117+28,0625 . \Delta z+0,555 . d+0,001223 . v-0,5 . d . v+0,75 . T$

Wherein: 
- $\Delta \mathrm{z}$ : The vertical feed rate in $\mathrm{mm}$,

- D: The diameter of tool in $\mathrm{mm}$

- V: The velocity of tool in horizontal plane in $\mathrm{mm} / \mathrm{min}$

- T: The temperature $\mathrm{T}$ of PVC sheet when forming in ${ }^{0} \mathrm{C}$

The regression equation of angle of deformation $\alpha$ was checked by Minitab ${ }^{\circledR}$ 15.1.30.0 software with the model results.

$\mathrm{S}=1,3911 \quad \mathrm{R}-\mathrm{Sq}=93,69 \% \quad \mathrm{R}-\mathrm{Sq}(\mathrm{pred})=91,93 \% \quad \mathrm{R}-\mathrm{Sq}(\mathrm{adj})=88,78 \%$

The result shows the reliability of the equation (1). With the R-Sq, R-Sq (pred) and $\mathrm{R}-\mathrm{Sq}(\mathrm{adj})$ value are all greater than $85 \%$ [7], meaning the regression equation are fit to the data. The Minitab diagram shows the effect of 4 input parameters to the deformable angle $\alpha$ in figure 8 .

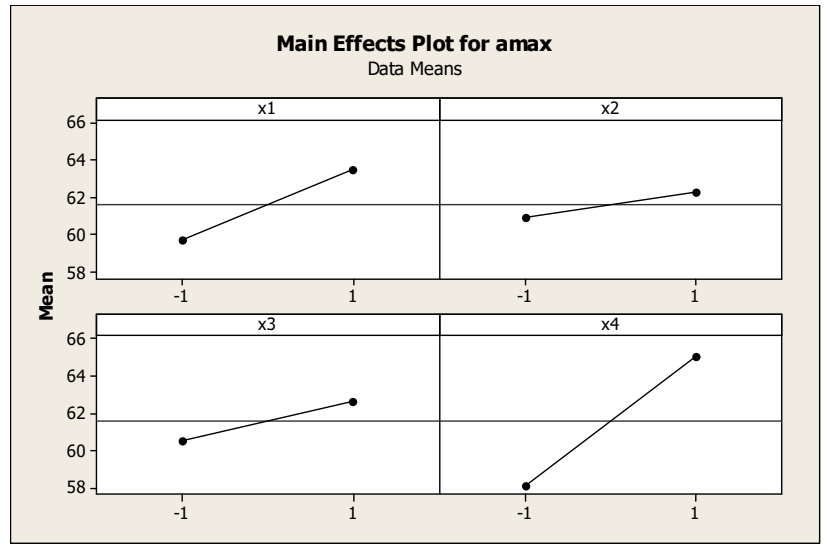

Fig. 8: Effects of 4 parameters on angle of deformability of PVC sheet

In examining the diagram in figure 8 we confirm that 4 parameters are also proportional to the angle $\alpha$ wherein the effect of $\mathrm{x} 4$ (stands for temperature $\mathrm{T}$ ) is greatest. So in order to increase the deformability of PVC we should increase all 4 parameters especially the temperature $\mathrm{T}$. However, according to [5] the maximum operating temperature of $\mathrm{PVC}$ is $140^{\circ} \mathrm{F}=60^{\circ} \mathrm{C}$ so $60^{\circ} \mathrm{C}$ is the maximum temperature that we could selected.

\section{CONCLUSIONS}

Finally, in one word we concluse an essential points: The formability of PVC sheet is proportional to all 4 selected influential parameters such as the vertical feed rate $\Delta z$, the diameter of tool $\mathrm{d}$, the velocity of tool $\mathrm{v}$ and the temperature $\mathrm{T}$ of PVC workpiece, therefore in order to increase the formability of PVC sheet we have to increase all of these parameters $\left(\Delta \mathrm{z}=1.2 \mathrm{~mm} ; \mathrm{d}=12 \mathrm{~mm} ; \mathrm{v}=2500 \mathrm{~mm} / \mathrm{min} ; \mathrm{T}=60^{\circ} \mathrm{C}\right)$ and $60^{\circ} \mathrm{C}$ is the maximum temperature that we could selected.

\section{REFERENCES}

1. E. Leszak. Apparatus and Process for Incremental Dieless Forming. Patent US3342051.

2. J. Jeswiet, F. Micari, G. Hirt, A. Bramley, J. Duflou, J. Allwood. Asymmetric Single Point Incremental Forming of Sheet Metal, Springer US, 2005. 
3. Wei H, Hussain G, Heidarshenas B, Alkahtani M, Post-Forming Mechanical Properties of a Polymer sheet processed by Incremental Sheet Forming: Insights into Effects of Plastic Strain and Orientationand size of Specimen, Polymers, 12(9), (2020).

4. S. A. Yonan, M. B. Silva, P. A. F. Martins, A. E. Tekkaya, Plastic flow and failure in single point incremental forming of PVC sheets, EXPRESS Polym. Lett., Vol. 8, No 5, (2014).

5. POLYVINYL CHLORIDE (PVC) PROPERTIES, International Polymer Solutions Inc., iPolymer, https://www.ipolymer.com/pdf/PVC.pdf.

6. V. Tuyen, N. T. Nam, N. P. Anh, L. K. Dien, T. K. Nguyen and T. L. Tran, A measure of Optimization of Parameters to Improve the Formability of Stainless-steel Sheet SUS 304 by SPIF Technology, Key Engineering Material, Vol. 863, pp59-66 (2020).

7. D. C. Montgomery. Design and Analysis of Experiment, John Wiley \& Sons, 2013. 